$12-31-2018$

\title{
Community engagement in teaching-learning: A pathway to quality education
}

\author{
Geraldine Villaluz \\ University of San Carlos Cebu City, gvillaluz2009@gmail.com \\ Mariter Malonjao \\ University of San Carlos Cebu City
}

See next page for additional authors

Follow this and additional works at: https://scholarhub.ui.ac.id/ajce

Part of the Social and Behavioral Sciences Commons

\section{Recommended Citation}

Villaluz, Geraldine; Malonjao, Mariter; Trinidad, Carina; and Bojos, Marlon (2018). Community engagement in teaching-learning: A pathway to quality education. ASEAN Journal of Community Engagement, 2(2). Available at: https://doi.org/10.7454/ajce.v2i2.133

Creative Commons License

(c) (i) ()

This work is licensed under a Creative Commons Attribution-Share Alike 4.0 License.

This Research Article is brought to you for free and open access by the Universitas Indonesia at ASEAN Journal of Community Engagement. It has been accepted for inclusion in ASEAN Journal of Community Engagement. 


\title{
Community engagement in teaching-learning: A pathway to quality education
}

\author{
Geraldine Villaluz $^{\text {** }}$, Mariter Malonjao ${ }^{a}$, Carina Trinidada, Marlon Bojos ${ }^{b}$ \\ ${ }^{a}$ University of San Carlos Cebu City, Philippines \\ ${ }^{b}$ Cebu Normal University, Philippines
}

Received: September 27th 2018 || Revised: December 26 $6^{\text {th }}||$ Accepted: December $30^{\text {th }}, 2018$

\begin{abstract}
In response to the demands of a changing educational system in the Philippines, this study sought to improve learning performance and faculty development through professional learning community engagement using a research lesson framework, a Japanese approach to professional development. The purpose is to identify how effective research lessons and community engagement can be in improving the quality of teacher and student performance. Using a narrative inquiry approach within a research lesson framework with four classes of Social Dimensions of Education and pre-service teachers, the study results netted a rich exchange of ideas, engaged student and teacher performance, and deconstructed the privacy of lesson planning.
\end{abstract}

Keywords: Research Lesson Framework; Teaching-Learning; professional community engagement

\section{Introduction}

This study aims to illustrate how the Professional Learning Community engagement and the kenkyuu jugyou or Lesson Study frameworks applied to a tertiary course named the Social Dimensions of Education can improve teaching-learning practices towards creating a sustainable working model for instructional development with the goal to answer the following objectives: 1. Identify experienced challenges and opportunities in the teaching-learning practices of Social Dimensions of Education; 2. Illustrate and analyze the significant effects of applied Lesson Studies to a formed Professional Learning Community in the areas of: a) Student learning performance, b) Teacher reflective practice and c) Professional Knowledge growth; and 3. Contribute a teaching approach as model that can best facilitate a research-based teaching-learning practice of teachers in the country.

The global standards of the ASEAN Integration propelled reforms in education toward achieving the Philippine Qualifications Framework (Atty. Manzala, 2013), the K-12 Reform, which enhanced basic education from 10 to 12 years (15th Congress of the 
Geraldine Villaluz, Mariter Malonjao, Carina Trinidad, Marlon Bojos | ASEAN Journal of Community Engagement | Volume 2, Number 2, 2018

Philippines, 2013), and the new teacher education curriculum ("Nationally-validated Version. Finalized, TEC Workshop, August 4-5, 2016 (C) PNU and UNE," 2016).

In our school community in Central Visayas, the School of Education with the rest of Higher Education Institutions in the country responded to these reforms in the areas of teaching learning and faculty development through seminar workshops and trainings on Outcomes-Based Education (OBE), module writing, group studies in teaching-learning and research. However, implementation for reform changes do not come easy especially when we work with long held norms, and accustomed practices, teaching behavior and attitudes. In addition, the current teaching practice basically pours in 99.9 per cent of time to class preparation, on-line research, assessment preparation, grade computation and meetings, in addition to personal and academic concerns. Reflection on one's teaching practice has been the area most neglected despite the structures of reflection papers, portfolios and journals provided for in professional education courses. These concerns in the teaching community called for a research-based knowledge and action.

Along with the rest of higher education institutions in the country, the School of Education at the University of San Carlos commenced using these reforms in the areas of teaching, learning, and faculty development through seminar workshops on outcomebased education, module writing, and group studies in teaching-learning and research. However, reform changes do not come easy when up against long-held norms, teaching behaviors, and attitudes. This concern called for research-based action.

While higher education institutions in the country awaited the revised teacher education curriculum in suspended anticipation, the School of Education translated its efforts into course development, module writing, planning, writing outcome-based syllabi, and researching teaching-learning practices. In addition to departmental concerns, this lacuna and the spirit of uncertainty brought about by the long wait opened space for experimentation inspired by a research-based Japanese approach to professional development popularly called lesson study. Four faculty members from the Physical Education, Montessori Education, Special Education, and Teacher Education programs organized a variation of this lesson study framework in the Social Dimensions of Education course (EDUC 102).

Social Dimensions of Education is a course in professional education that introduces social science theories within the context of social and educational concerns in Philippine 
Geraldine Villaluz, Mariter Malonjao, Carina Trinidad, Marlon Bojos | ASEAN Journal of Community Engagement | Volume 2, Number 2, 2018

and other world societies. However, the new teacher education curriculum enhanced this course by adding school culture and organizational leadership dimensions; thus, the current course has acquired a broader perspective and has a new course title: The Teacher and the Community, School Culture and Organizational Leadership (CHED [Commission on Higher Education], 2017, p. 44).

The engaged faculty community in this study have regularly taught this course for five consecutive years. Reflective discussions and analysis of the course syllabi and delivery revealed a need for unified goals, reorganization of content and assessment, as well as organization and good planning toward outcome-based knowledge and skills. Inspired by the spirit of experimentation and the positive results from the existing literature on research lessons, the four faculty members ventured on the research lesson project in the Social Dimensions of Education course during the second semester of 2016-2017.

This study aims to illustrate how engaging the professional learning community and applying kenkyuu jugyou or research lessons to the Social Dimensions of Education course can improve teaching-learning practices and create a sustainable working model for instructional development with the goal of meeting the following objectives:

a. Identify challenges and opportunities experienced within the teaching-learning practices of the Social Dimensions of Education course;

b. Illustrate and analyze the significant effects of applied research lessons in professional learning community engagement to teaching-learning practices in the areas of: Student learning performance, Teacher reflective practice, and Professional Knowledge growth.

Results of this study will be most significant for teaching-learning professional communities in General Education and Senior High School, as well as for tertiary level teachers who handle the same courses. In-service and pre-service teachers can learn from the process of creating model lessons together, acquire the discipline for professional knowledge, and develop intrapersonal reflective discipline. Education researchers benefit most from post-lesson discussions and the processes of the research lesson cycles because data retrieved from the research are practice based. Reflection sessions in the post conference cycle can serve as models for teachers at all levels as they prepare for beginning and professional career stages prescribed in the Philippine Professions Standards for Teachers (Philippine Normal University \& UNESCO, 2016, p. 9). 
Geraldine Villaluz, Mariter Malonjao, Carina Trinidad, Marlon Bojos | ASEAN Journal of Community Engagement | Volume 2, Number 2, 2018

To illustrate how lesson studies impact areas of student performance, teacher reflective skills, and professional knowledge development, this study was built on the research lesson framework and on two working theories; namely, the reflective practice and constructivism theories of John Dewey, Donald Schön and Lev Vygotsky.

\subsection{Professional Learning Communities}

"Knowledge is a social construct" has been a popular statement circulating among social constructivist theorists such as John Dewey, Lev Vygotsky, and followers of constructivism like Donald Shön. In his book Democracy and Education, John Dewey argues that communication is an important element of creating communities. It is through communication that human beings can share goals, beliefs, aspirations, and knowledge. When members of a community share a common understanding and, in Dewey's words, "common emotional expectations", their participation can be assured (Dewey, Democracy \& Education, 2008). Social construction of knowledge in the constructivism theories of John Dewey (1910), Jean Piaget (1950), and Lev Vygotsky (1962) serve as powerful tools for deconstructing deteriorated work ethics and placing reflection practices into the work structure of professional learning communities. However, knowledge reconstruction can be a slow process, especially when it is done individually or in isolation. However, when the community shares aspirations, dreams, and expectations, the process of deconstructing past concepts and reconstructing a new focus and understanding can be facilitated by a community of learners. John Dufour call these communities professional learning communities, now popularly called PLCs (Dufour, 2004, p.3).

\subsection{Constructions in Teaching-Learning}

Faculty members who follow the constructivist theory in teaching-learning engage in collaborative work to create a professional learning community. Teachers involved in PLCs actively involve themselves in planning-implementation-observation-analysis and reflection processes, which are the key attributes for deconstructing habitually formed norms, beliefs and routine. This is emphasized as a value to professional learning communities in studies by Hord (2009) and Dufour (2004), which have been part of the educational reform movement in the United States. DuFour identifies three "big ideas" to sustain professional development among teachers: One is to focus on student learning 
Geraldine Villaluz, Mariter Malonjao, Carina Trinidad, Marlon Bojos | ASEAN Journal of Community Engagement | Volume 2, Number 2, 2018

instead of teaching; the second is building a culture of collaboration among teachers; and the third is to judge success based on results (Dufour, 2004, pp. 1-6). Hord (2009) adds six conditions for successful professional learning community engagement: a) membership in a professional learning community; b) important leadership roles held by principals or administrators; c) finding time for learning and research in meetings; d) space for learning; e) review, study, interpretation, and reflection on data as core elements of PLC; and f) distributed shared leadership (Hord, 2009, pp. 42-43).

These two theories on reflective practice and social knowledge construction serve as the core structures that support the processes of the research lesson frameworks used in this study. It is the processes of constant planning, implementation, observation, and reflection that resulted in changes to the syllabi and in teaching strategy and personal teaching-learning awareness by members involved in this research lesson team.

\subsection{Research Lessons}

Kenkyuu Jugyou or Research Lesson is a Japanese professional development approach in teaching-learning which started in the early 1900s, specifically during the Meiji period. This was a time when Western science and technology were introduced through American teachers who were experienced in teacher training (Makinae, 2010). During this period, the criticism-observation method of teacher training for pre-service and inservice teachers was practiced in local elementary schools and normal schools in Japan; it was popularly called Jugyo-hihyo-kai or criticism lesson conference. This later developed into lesson study conference or Jugyo-kenkyu-kai in Japanese (Lewis, 2000, p. 3).

\subsection{Research Lesson Framework}

Kenkyuu, which means study or research, and jugyou, meaning lesson, describe the process of observing and refining live lessons to improve teaching practices and enhance student learning using planned lessons created by a team of teachers. Literature popularly calls this process lesson study. However, this paper will use the original words kenkyu for research and jugyou for lessons, as explained by Lewis (2000). The four basic elements of research lessons documented by research practitioners include: a) Lesson Planning, where the team identifies the goal toward which all the lessons are directed; b) 
Geraldine Villaluz, Mariter Malonjao, Carina Trinidad, Marlon Bojos | ASEAN Journal of Community Engagement | Volume 2, Number 2, 2018

Implementation of the planned lesson by one team member; c) Team Observation of the implemented lesson; d) Post Lesson Conference; and e) Reflection on the observed lesson. The literature emphasizes that the focus of every observation should be in the area of student engagement and their learning processes (Lewis, Perry, \& Hurd, 2004, p. 20); (Lewis \& Lewis, 2000 pp. 4-6); (Robinson \& Leikin, 2012, p. 139-140); (Fernandez, 2002, p. 394).

Researchers agree that the research lesson or lesson study is an ongoing process of planning-teaching-observation and reflection. Lesson Study practitioners from the University of the Philippines National Institute for Science and Mathematics Education reiterate that a significant element of the lesson study "is not the product but the process". It is within the process of continuous observation, discussion, reflection, and revision that a planning team of teachers develop professional growth from their individual and group insights as they evaluate their own teaching practices (Wang Iverson as cited in Soledad Ulep et. al, 2014). The research lesson framework incorporates the element of reflection into the last step of the cycle, which educators and philosophers of education consider the most significant.

Each research lesson is followed by sharing observations and individual reflections on the shared observations of the planning team. Instead, current teaching practices typically pour $99.9 \%$ of time into class preparation, online research, assessment preparation, grade computation, meetings, and personal and academic concerns. Reflection on one's own teaching practice is the most neglected area despite the structures provided in professional education courses such as reflection papers, portfolios, and journals. This paper will establish the importance of reflective practice and how it significantly affects knowledge formation from the theories of John Dewey, Jean Piaget and Donald Schön.

\subsection{Reflective Practice Theory}

In his book How We Think, John Dewey (1910) asserts that reflection or reflective practice deepens and clarifies created knowledge for both teacher and learner because reflection is a process that builds on experience, knowledge, and feelings, so it opens a pathway to new knowledge learned through present encounters. According to Dewey, past knowledge is therefore a building block to new knowledge. He claims that learning 
Geraldine Villaluz, Mariter Malonjao, Carina Trinidad, Marlon Bojos | ASEAN Journal of Community Engagement |

Volume 2, Number 2, 2018

becomes meaningful only when it is "given active, persistent and careful consideration for responsible action" (Dewey, 1910, p. 6). Dewey also argues that "routine action or habit which is automatic may increase skill; it may have an educative effect, but it does not lead to new perceptions or connections; it limits rather than widens the meaning-horizon" (Dewey, 1910, p. 116).

In effect, a reflection journal should be composed of: a) past knowledge or experience, and feelings on the matter at hand; b) current perceptions of the matter at hand; and c) responsible action (Dewey, How We Think, 1910, p. 29-44). Dewey's process of looking back on experience and past knowledge using reflective thinking supports Jean Piaget's organization and adaptation in the development of intelligence. In his book, The Psychology of Intelligence, Piaget (1950) asserts that advancement in thinking is achieved when one goes through a readjustment or reconstruction of thoughts between old and new schemes to modify and accommodate a new idea (Piaget, 1950, pp. 8-9). Thus, reconstruction based on the reflection process suggests an act of careful weighing, calculation, or examination of data to reorganize past data with a broader level of understanding (Dewey, The Means and End of Mental Training: The Psychological and the Logical, 1909, p. 57).

In addition, Donald Schön (1983) argues that there is a difference between practitioners and reflective practitioners. In his book The Reflective Practitioner, Donald Schön, using Birgitte Michelsen as an example, differentiated a practitioner who knows in action from a practitioner who reflects in action. Schön argues that knowing in action is a reflexive act, decision, or judgment done spontaneously and actuated by learned principles, training, set norms, or internalized understanding of a certain discipline. On the other hand, according to Schön, reflection in action surfaces and critiques the assumed or unspoken understanding of a concept that has been accepted as norm through routine repetition of "specialized practice" (Donald Schön, 1983, pp. 1-3).

In reflection, Schön identifies various areas which a practitioner can draw out into conscious awareness such as "feelings that led to a decision or action, the unspoken norms or practiced concepts and theories left unquestioned, and one's role in an institution or organization". Schön asserts that reflection generates new understanding of a problem and how to change the situation. He says that "when one reflects, he becomes a researcher in the practice context. He is not dependent on the categories of established theory and technique but constructs a new theory of the case" (Donald Schön, 1983, p. 2). 


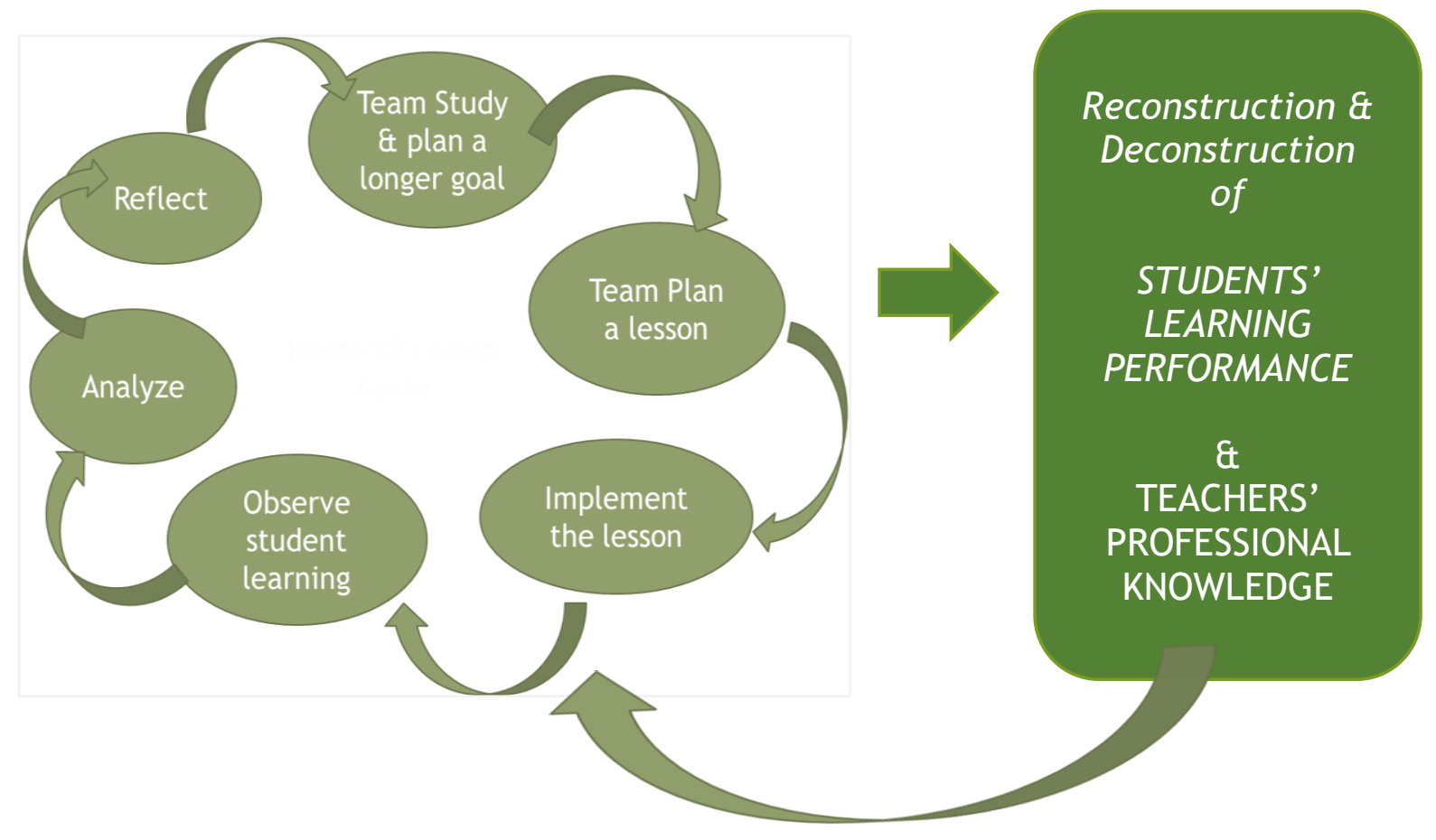

Fg. 1 Research Lesson Framework: A variation of the framework from Catherine Lewis' Study, 2011

The research lesson process involves six steps with a focus on continuously deconstructing and reconstructing norms, beliefs, attitudes, and knowledge in the teaching practice and bringing the processes of how students learn to the surface. The first step is team-sharing of gaps, resources, and data on student learning performance and setting a long-term goal; the second step in the cycle is planning a lesson together where one member of the team volunteers or is chosen to facilitate the planned lesson. Observation of the lesson implementation is the third step; this is where the team notes how students learn and why students do not learn. In the observation stage, the team leader orients the team and guest observers to the long-term goal and lesson objectives. A protocol questionnaire is given to each observer. Some observers may be tasked with considering different areas of teaching-learning such as the learning needs of specific students, and the processes of learning among the student majority. The fourth step is a team analysis of the observed learning processes of students.

The data noted by the team and guest observers are discussed in the post-lesson evaluation. A reflection session of one's experience in the research lesson and a sharing of insights from the different observations concludes the whole cycle. A revision of the first research lesson is planned by the team based on the data gathered from the 
Geraldine Villaluz, Mariter Malonjao, Carina Trinidad, Marlon Bojos | ASEAN Journal of Community Engagement | Volume 2, Number 2, 2018

observations of the first lesson. This time, another member of the team facilitates the planned lesson. The cycle is repeated until the long-term goal is achieved.

\section{Methods}

This study uses a qualitative research that applied the narrative inquiry method in the research lesson framework using conversations, dialog, observations, and reflection as sources of data. As prescribed in an inquiry-based method, repetitive inquiry was used with reflection as a grounding principle that guided the entire process before, during, and after each lesson implementation (Given, 2008, pp. 541-544). The selection of teacherparticipants for this research lesson was based on Shirley M. Hord (2009) and Richard DuFour's (2004) characteristics of a professional learning community, which specify that the team must have the required time to meet, plan, and reflect on data gathered (Dufour, 2004, p. 4); (Hord, 2009, p. 42).

The faculty team engaged in this study have regularly taught this course for five consecutive years and have expressed commitment for meeting sessions required in the research lesson framework. Inspired by the spirit of experimentation and the positive results from literature on Professional Learning Community and Lesson Study, the four faculty members ventured on the research project in the Social Dimensions of Education course in the second semester of 2016-2017.

Student participants of the study came from four classes of 151 third-year students of the Social Dimensions of Education course who were managed by four faculty participants from the research lesson team. The respective teacher in charge gave each class an orientation on the objectives for the semester's course using research lessons as a framework for course enhancement. Ethical considerations were made in carefully presenting the student and faculty voices to express the feedback which was carefully gathered through class focus group discussions, video and photo documentation. Documentation included planning sessions, lesson implementation, post-lesson evaluation, and reflection sessions at the end of each research lesson. Verbatim field texts from the class and team focus group discussions are coded into three areas: a) student learning performance; b) professional development; and c) research practice. Significant texts are aligned with themes that support the data with audible presentation of respondents' voices. 

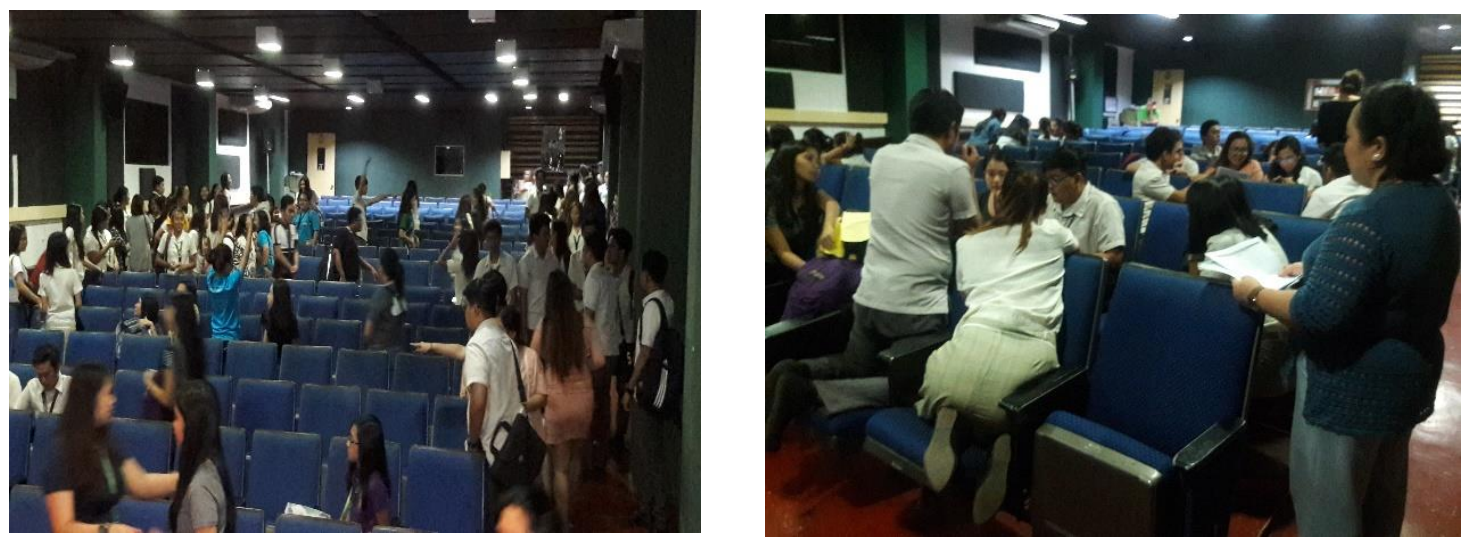

Fg. 2 Research Location: Anthony Buchcick Hall, February 17, 2017

Normally. research lessons are observed in one classroom (Lewis, 2000, pp. 4-6). In this research lesson, however, the research team decided to hold all four classes in the audio-visual hall of the School of Education as one class. Since all four classes did not have a schedule in common, the research lessons were scheduled at one time, on Fridays from 5:30-7:30 in the evening. The audio-visual hall is situated on the ground floor of the School of Education, in the Anthony Buchcik building, which has a 300-seating capacity. The permanent structure of the seats in the audio-visual facility did not create a limitation because students freely sat facing each other or in circles on the floor.

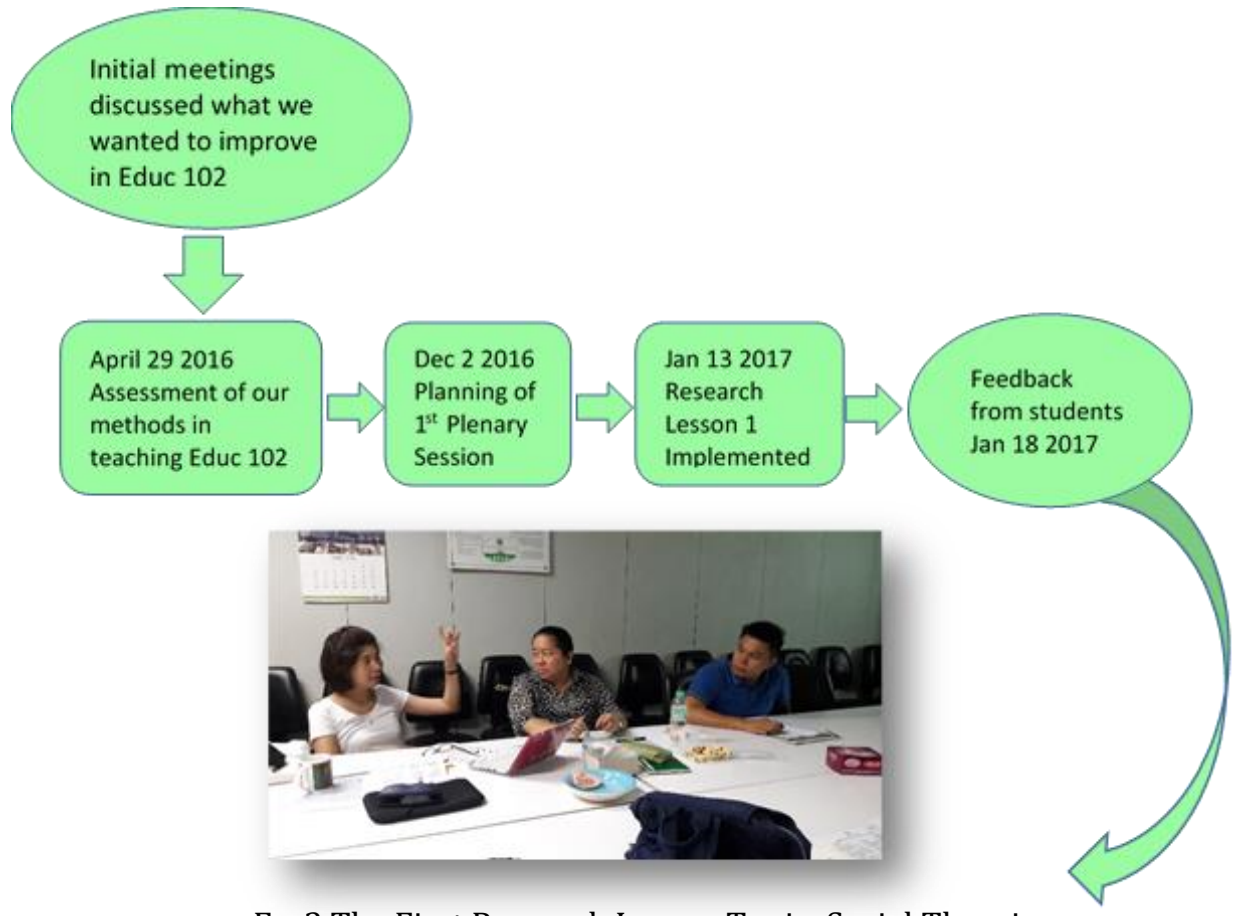

Fg. 3 The First Research Lesson Topic: Social Theories 
Geraldine Villaluz, Mariter Malonjao, Carina Trinidad, Marlon Bojos | ASEAN Journal of Community Engagement | Volume 2, Number 2, 2018

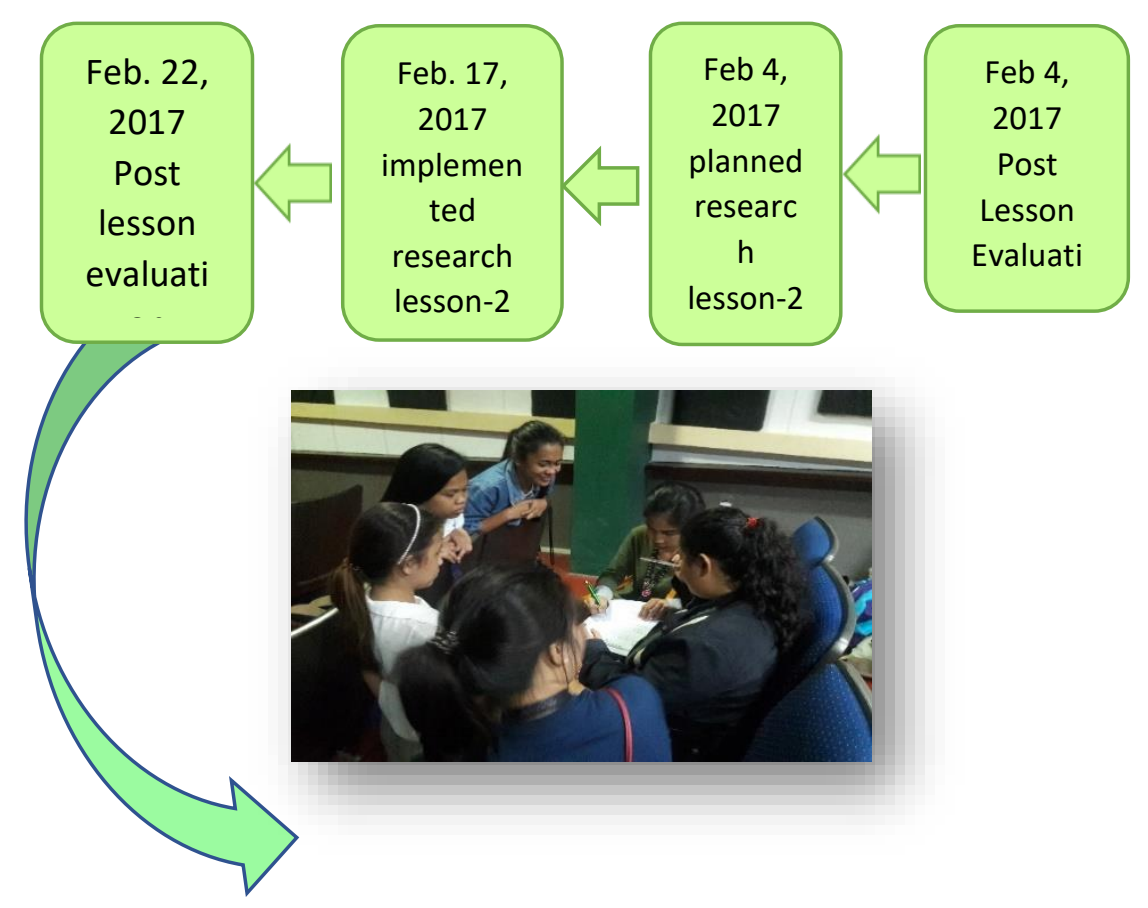

Fg. 4 Second Research Topics: Family and Church Institutions Affecting Education

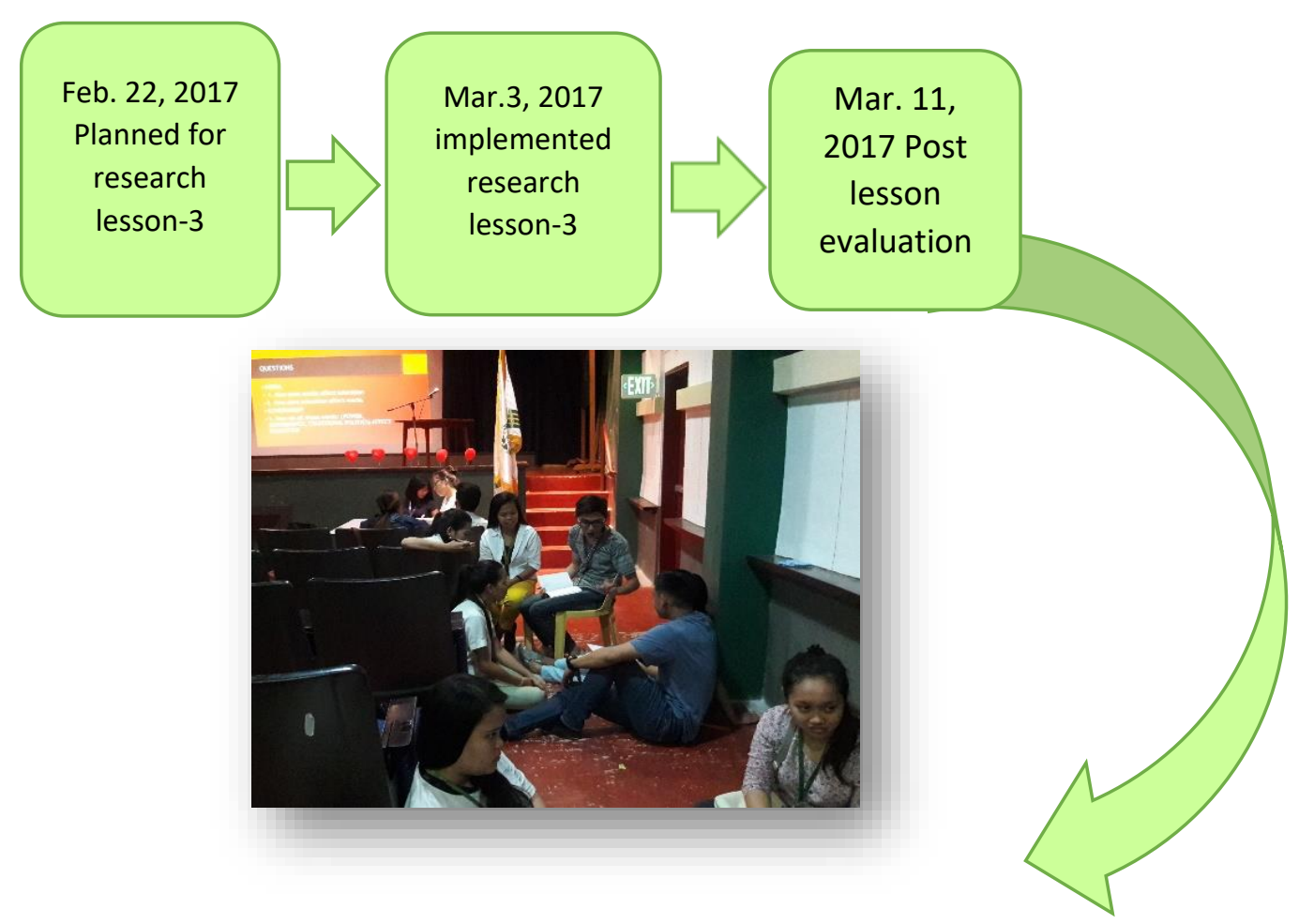

Fg. 5 Third Research Lesson Topics: Governance and Media affecting Education 


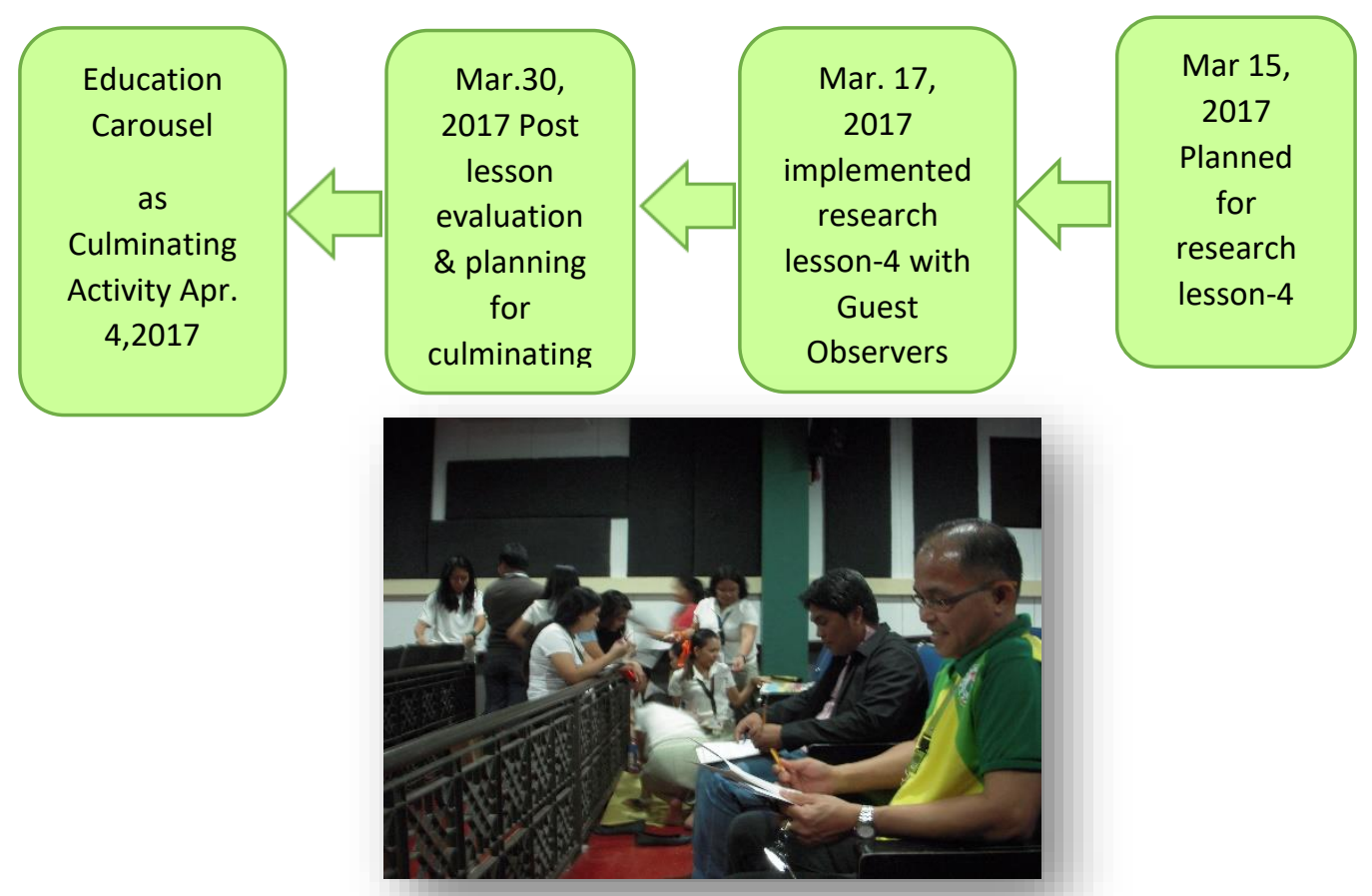

Fg. 6 Fourth Lessons Topic: Globalization with Guest Observers

\section{Result and Discussion}

The research lesson began with the gathering of four faculty members from the School of Education who hailed from a Montessori Education program, a Special Education program, a Physical Education program, and the Teacher Education program who were all teaching the same course: Social Dimensions of Education (EDUC 102). During a gathering on April 29, 2016, each faculty member realized that in three years of their teaching-learning experiences in EDUC 102, their teachings all differed in content, culminating activities, and assessment. They made a commitment to experiment with a course development framework called lesson studies or research lessons.

Several areas in the teaching-learning processes were examined, including the resources, available materials, course content, community resources, teaching strategies used, and gaps encountered. The team shared individual learnings and insights in teaching EDUC 102 that revealed that they each treated the course with different course content, assessment styles, and culminating outcomes each year. Shared observations on student performance identified poor reading comprehension and critical thinking among students, as well as a low confidence in the articulation of ideas in class. 
Geraldine Villaluz, Mariter Malonjao, Carina Trinidad, Marlon Bojos | ASEAN Journal of Community Engagement |

Volume 2, Number 2, 2018

Teacher 1: We have observed that $90 \%$ of our students lack reading comprehension and articulation skills;

Teacher 2: They simply repeat what they read

Teacher 3: Association of concepts is poor

Teacher 4: Analytical skills is poor

Teacher 3: Students lack confidence in sharing their ideas to an audience

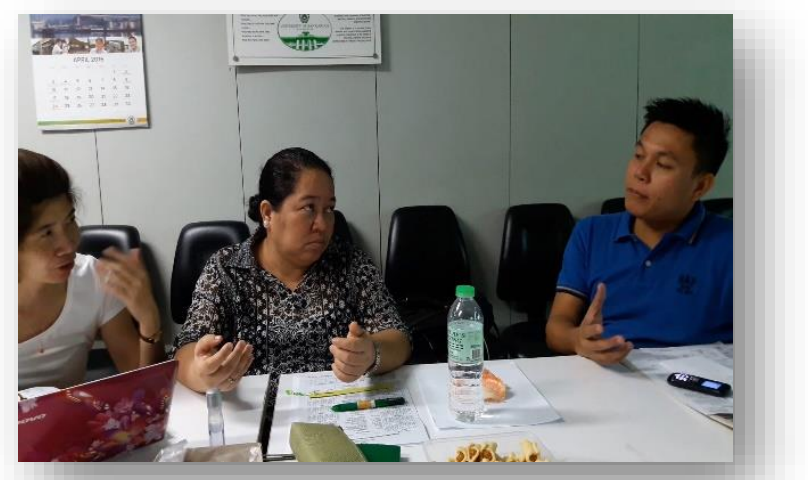

Fg. 7 Research Lesson Team Assessment \& Observation of Teaching-Learning Experiences in Educ 102. April 29, 2016.

The output from this sharing session became three course outcomes for EDUC 102 in the second semester of 2016-2017: Course Outcome 1 was to demonstrate the social skills needed for community networking and event organizing while consciously applying the principles of inclusivity, collaboration, and mission orientation; Course Outcome 2 was to identify and analyze the social dynamics and leadership skills experienced in the group planning-preparation-implementation-evaluation stages of a social event according to the standards of a research lesson cycle; and Course Outcome 3 was to present best practices that strengthen the value-laden skills of the team, including inclusive organizing, collaborative networking, and compassionate sharing. For logistical purposes, we organized ourselves by task and chose a team leader to guide us through the research process.

Each team member was tasked with a set of literature reading on research lessons, some sample lessons, and video illustrations from youtube.com. The first research lesson planning was set for December 2, and it was implemented by a volunteer facilitator from one member of the team on January 13, 2017. A post lesson 1 evaluation was conducted with students, who provided the following remarks: 
Geraldine Villaluz, Mariter Malonjao, Carina Trinidad, Marlon Bojos | ASEAN Journal of Community Engagement | Volume 2, Number 2, 2018

Student-1: it was like a typical group report session ("murag typical group reporting ra")

Student-2: "Not effective. Most of the presenters were just oral reading" Student-3: "there was only 5\% interaction between presenters and audience" Student-4: "Presenters were not ready; they were just facing their slides" Student-5: the presenters did not seem to understand what they were reading ("the presenters, murag wala kasabot sa ilang gibasa")

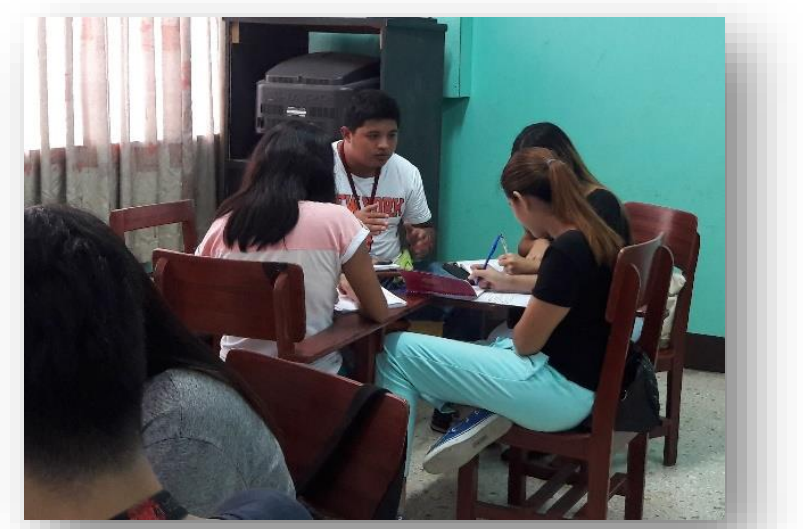

Fg. 8 Excerpts of Students feedback from research lesson 1. January 18, 2017.

A post lesson 1 observation of the faculty team on February 4, 2017 revealed the following:

Teacher1: "The discussion of social theories was not contextualized"

Teacher2: "there seems to be a culture of shyness in our students to ask questions in plenary"

Teacher3: “reporting by groups doesn't seem to work especially when they are tasked to read

Teacher4: "One good thing about the first lesson is that our students witnessed the four of us working together to facilitate and observe each group. I believe that was a good witnessing"

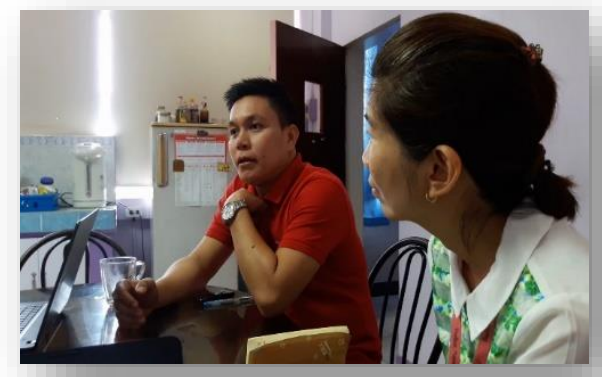

Fg. 9 Excerpts of post lesson 1 Evaluation by the research lesson team. February 4, 2017 
Geraldine Villaluz, Mariter Malonjao, Carina Trinidad, Marlon Bojos | ASEAN Journal of Community Engagement |

Volume 2, Number 2, 2018

Excerpts from the research team post lesson 1 reflection:

Teacher1: "Let us choose a topic that is closer to students' life experience"

Teacher2: "We need to orient our students' roles in group sharing; choosing a facilitator, documenter, timekeeper and one to represent the group to share a synthesis of the group discussion in the plenary"

Teacher3: "perhaps we need to task some students to do their own photo documentation as well"

Teacher4: "I suggest that we also start the lesson on schedule. It is not good modeling to our students to start the lesson 20 minutes late"

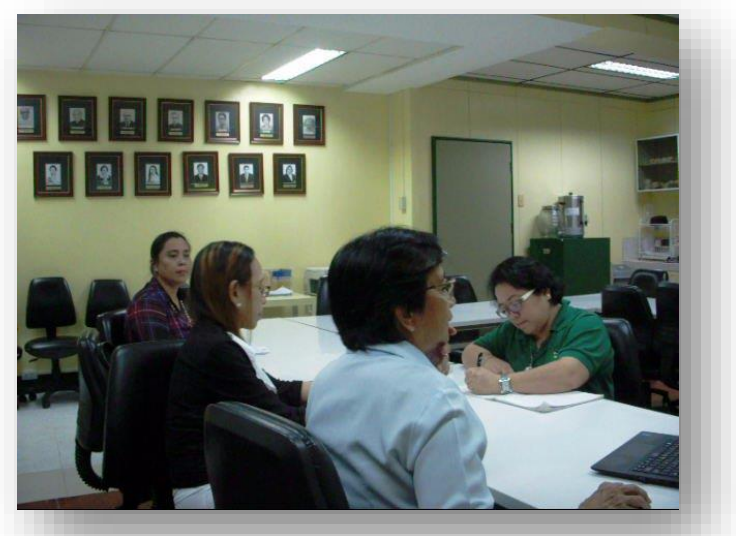

Fg. 10 Excerpts of planning for Research Lesson 2

The team revised the lesson and planned a more engaging topic for the second research lesson. One member of the team implemented the lesson while the rest of the team observed and gathered data on student learning. Synthesis of the session was done by the students. Feedback from the students was also gathered on teaching strategy and on student learning.

\section{On Teaching Strategy}

Student 1: instead of using reporting as a strategy where decision is left to the leader and members simply depend on the leader, this strategy allowed each member of the group to share her/his ideas. Instead of using reporting as a strategy nga ang leader ray magbuot unya magsalig lang ang ubang

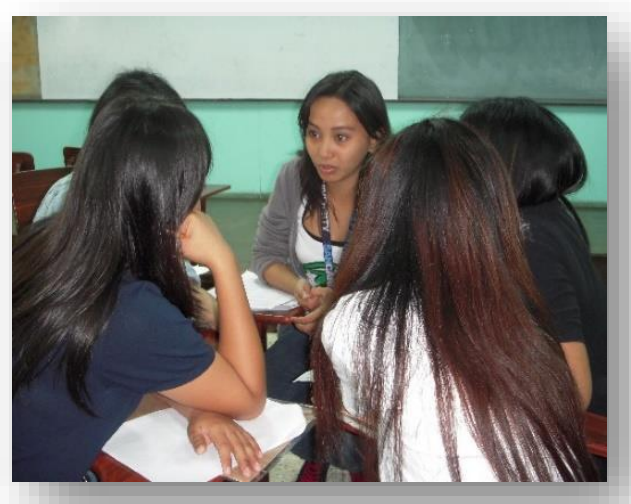

Fg 10. Excerpts from Student Feedback on research lesson 2 
Geraldine Villaluz, Mariter Malonjao, Carina Trinidad, Marlon Bojos | ASEAN Journal of Community Engagement | Volume 2, Number 2, 2018

members; karon maka share ang tanan sa grupo

Student 2: It was a very good approach. We were able to interact with other classes Nindot nga pamaagi, kay nagkaila mi sa ubang klase.

\section{On Student Learning}

Student 3: we were able to reflect from the sharing of members in the group "Basi sa gishare sa uban, makareflect gyud mi". Student 4: student participation was evident; if it were given in a lecture approach there would be students who will simply play with cell phones at the back. Makita ang participation sa kada estudyante; kung lecture ra to naa gyuy uban nga magtanga lang or magcellphone lang.

Student 5: there was lack of open forum in the synthesis part "In the synthesis, kulangan siya ug questioning"

Excerpts from the research team post lesson 3 reflection:

Teacher 1: "I have observed that our students are not exposed to governance and politics, so we need to give emphasis on these topics in our module for the new curriculum"

Teacher 2: "They are not so familiar with picture analysis that is the reason why they had a hard time recognizing the meanings of the pictures in the opening slides" Teacher 3: “The group sharing strategy capacitated our students' skills in facilitating, documenting and reporting"

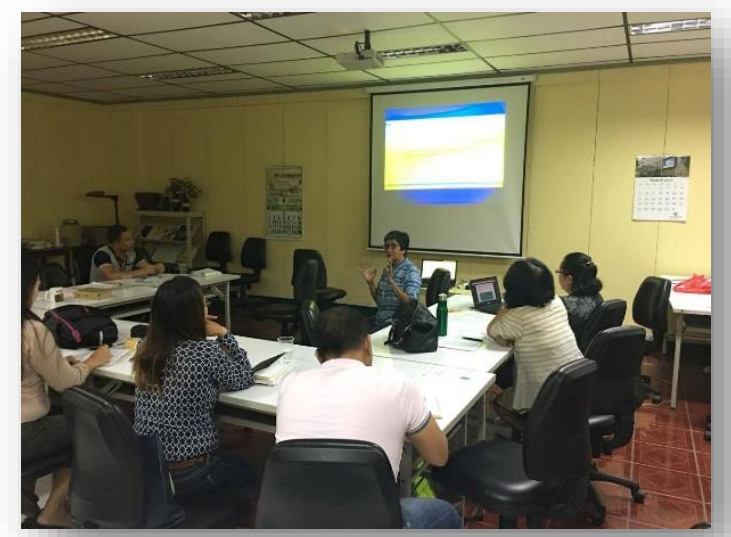

Fg. 11 Excerpt from Education Community's Discussion on Research Lesson 3 
Geraldine Villaluz, Mariter Malonjao, Carina Trinidad, Marlon Bojos | ASEAN Journal of Community Engagement |

Volume 2, Number 2, 2018

Four research lessons were implemented, allowing each team member the chance to implement a lesson. The fourth research lesson was observed by guest teachers from basic and higher education institutions of another school outside Cebu City. Guest observers joined the groups and listened to small group discussions. A post-research lesson 4 evaluation was conducted where observers provided feedback on student engagement and the prepared research lesson.

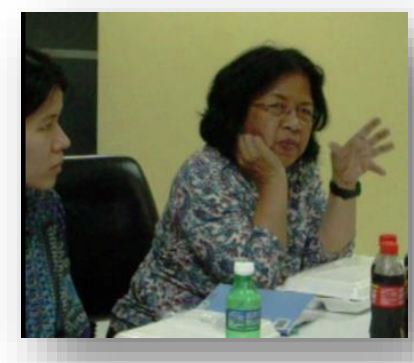

Dr Charito Pizarro

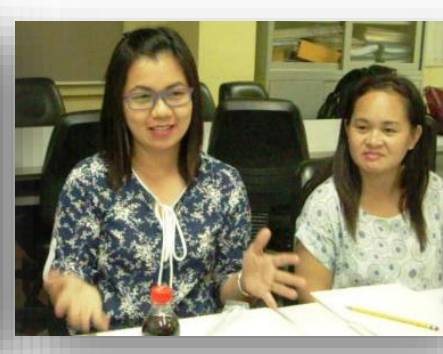

Mrs. Christine Enrile

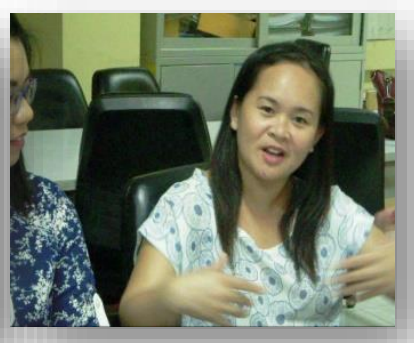

Mrs. Haydee Montero

Fg. 12. Guest Observers' remarks and feedback after the fourth research lesson (1)

Observer 1: "they can interact, yes, the excitement to meet other classes; not only among themselves"

Observer 2: "they were, give the authority, and like what Miss Haydee said, 'boost their confidence' because they are experts and as an expert, they know they can also share"

Observer 3: "during the collaboration among the students, uhm I also saw some who were not participating, there were selective few who really did the effort to discuss and to manage the concept in the collage";

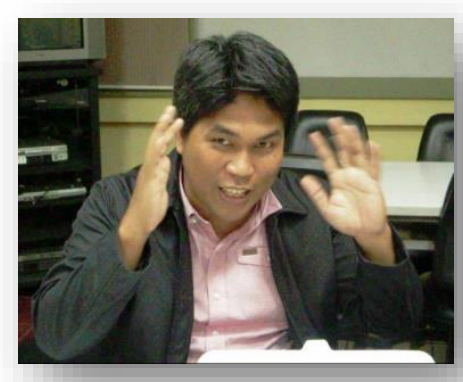

Mr. Carlito Casas

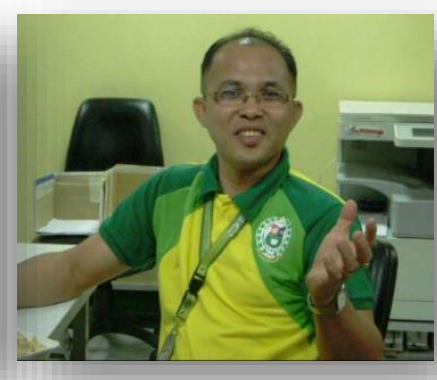

Mr. Saturn Mayormita

Fg. 12. Guest Observers' remarks and feedback after the fourth research lesson (2) 
Geraldine Villaluz, Mariter Malonjao, Carina Trinidad, Marlon Bojos | ASEAN Journal of Community Engagement | Volume 2, Number 2, 2018

Observer 4: "They had something to share to others, so it's like as I have said uhh empowering them"

Observer 5: "I think after that, because of the support of each other, they take ownership of what they have learned. And one of the good evidences that I found out is that the structure from small group to bigger group, how they recognized their ideas from small to bigger group.

These comments and suggestions were all noted to prepare for the course culminating performance at the end of the semester which was an Education Carousel where each class prepared an interactive learning session to invited children from the community outreach involvement of each class

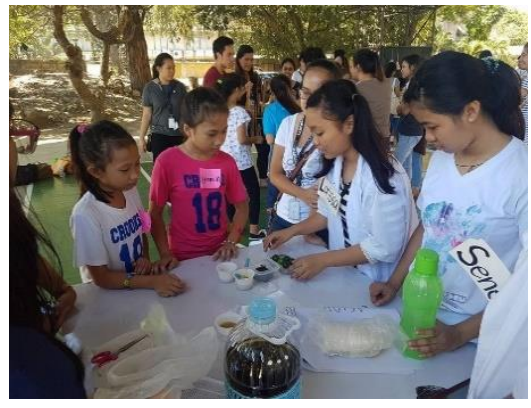

Chemistry Magic with camote tops leaves and lemon juice

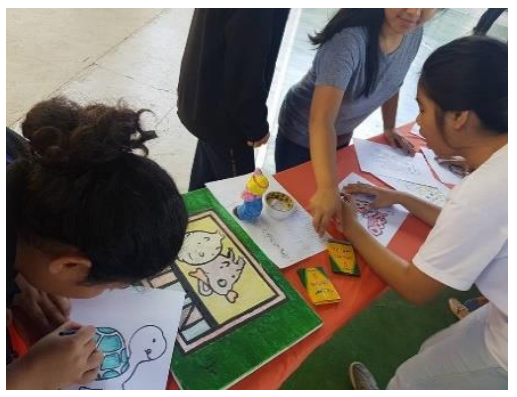

Story \& drawing corner

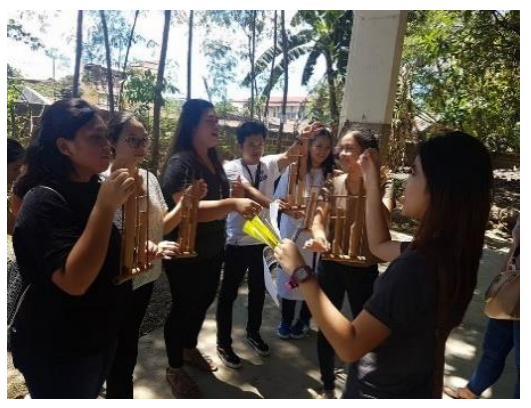

Angklung Music Booth

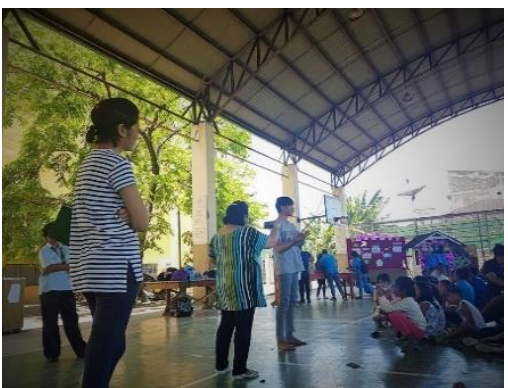

Sharing of insights \& feelings from the activities

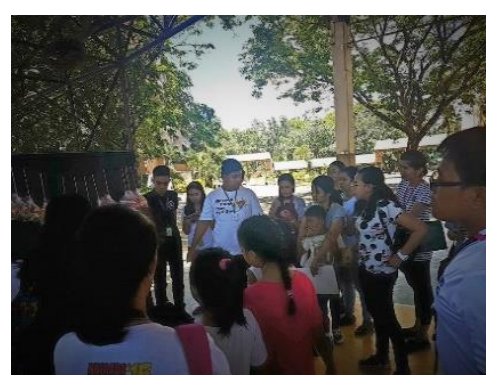

Outdoor Games

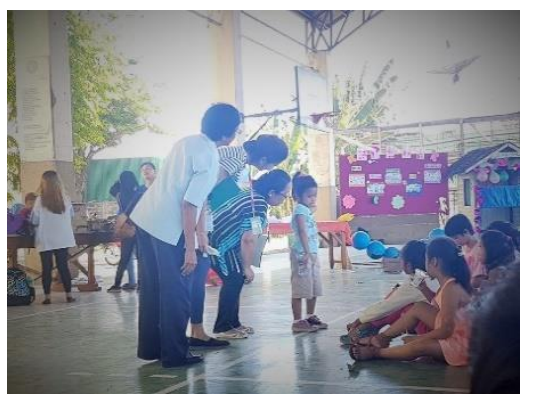

Sharing of 'what I learned'

Fg. 13 Culminating Outcome: Interactive Learning Carousel. April 4, 2017.

The carousel of interactive learning served as an authentic assessment of the semester's course and as a synthesis of the topics on social theories and institutions that impacted education, leadership and communication skills, and globalization and governance. Assessment of student learning included: a) attendance and participation in 
Geraldine Villaluz, Mariter Malonjao, Carina Trinidad, Marlon Bojos | ASEAN Journal of Community Engagement | Volume 2, Number 2, 2018

the four plenary research lessons and the culminating activity; b) individual journal; and c) student documents gathered from activities.

The application of two frameworks the Professional Learning Community (PLC) and research lesson in a professional Teacher Education course and to pre-service teachers resulted to changed perspectives in five areas of teaching-learning: a) Collaborative lesson planning, b) collegial community relationship, c) initiated reflective practice, d) broadened professional knowledge, and e) contextualized student learning outcome. Each of these areas led to a unified result in student learning outcome and needs to be given equal attention individually. However, the dynamism brought in by a professional learning community engagement and the processes of research lesson contributed a unique character to student learning outcome where all these areas in teaching-learning are addressed simultaneously as one.

\subsection{Collaborative Lesson Planning}

Private or individual lesson planning within one's field of discipline is common in the teaching practice and has become habitual in the teaching profession. Faculty in the school of education stay within the confines of one's disciplinal comfort zone, read literature and socialize with colleagues who share one's discipline. Knowledge in content instruction, teaching strategies, resources and opportunities revolve around the circle of the same academic discipline. The routine practice of specialized knowledge displaces reflective critical thinking and isolate teachers in personal cubicles. In this study the sacred privacy of disciplinal lesson planning was successfully deconstructed by the structure of both professional learning community engagement and research lesson framework because the collaborative activities involved in the sharing of strategies, lesson content seen from multiple disciplines, team observation, evaluation and shared reflection ensured an enriched lesson outcome. This was affirmed by members of the research team in one reflection session:

Collaborative lesson planning initiated in this study by a team of teachers from the disciplines of Physical Education, Montessori Education, Special Education and Cultural Education enriched content, instructional strategies, course goals and assessment of the Social Dimensions of Education (EDUC 102) and Pre-Service Teacher Education (EDUC 135) courses. 
Geraldine Villaluz, Mariter Malonjao, Carina Trinidad, Marlon Bojos | ASEAN Journal of Community Engagement | Volume 2, Number 2, 2018

\subsection{Collegial Community Relationship}

It is not only content and instructional strategies that have been transformed as a result of the study but collegial relationship among team members was developed. At the end of one reflection session of Research Lesson 2 one team member remarked:

“We have been meeting frequently for our students' lessons, observing, evaluating and reflecting together, perhaps it would be good to get to know each other and share how we started in the teaching profession".

Teacher 3. Post Reflection Session of Research Lesson 2

This remark from a faculty in Physical Education has prompted a lively sharing of how we all started as teachers and the reason why we chose the teaching profession. The sharing clarified a common understanding of personal goals and expectations in the teaching profession. This openness generated trust and confidence among members of the learning community.

It must be noted that in the Filipino culture a good working relationship with fellow workers plays an important role in the work place. This study has proven that shared meanings deepened each one's commitment to the research lesson and to the teaching profession. The bond that was developed among members of the learning community was received and felt by students of the four classes who saw their teachers working together as one in a class session. Two statements of team members have addressed the significance of a community of professionals who were teaching and learning as one:

Teacher 1: "Students sensed that the teachers were doing their tasks, as we went around to different groups"

Teacher 2: "There was openness among us teachers and this message was sent across to our students"

Teacher 5: "This is what teaching is all about; to take time to ask each other"

\subsection{Communal Reflective Practice}

Teacher professional courses in the Philippines have incorporated the reflection journal as one of the formative assessments to ensure a reflective discipline to every graduate of the teaching profession. However, the multi-task nature of the teaching profession has naturally removed the space and time from teachers to be able to write or 
Geraldine Villaluz, Mariter Malonjao, Carina Trinidad, Marlon Bojos | ASEAN Journal of Community Engagement |

Volume 2, Number 2, 2018

recall feelings, learnings, insights and aspirations that happened during the day in the classroom. This area in teaching has been most neglected and neither is it given enough attention in teacher trainings and workshops. Engaging members of a learning community to a regular schedule of reflection proved to be a challenging task for the team leader of the research lesson. The structure built into the research lesson framework however has brought reflective practice into place. The spirit of collegiality that was opened by the sharing of our personal stories as teachers added to the trust and commitment to participate in the post lesson evaluation - reflection processes.

During these sessions members of the team find the space to recall personal feelings, best practices and challenging practices during class time that needed to be documented and shared with a community. Encounters of this kind with fellow teachers paved the way to spontaneous voluntarism in team tasks, openness in asking for clarification of past knowledge, and facilitated a pathway for new knowledge in the teaching-learning process. Gradually shared thoughts during reflection session revealed our strengths and weaknesses and our realizations that we need to learn from each other to grow professionally.

Teacher 3: "Because of this approach this has given me a foundation of my own lesson in class that paves the way to an in-depth interactive discussion in the classroom";

Teacher 4: "I have gained new ways and methodologies in teaching"

Teacher1: "we have learned to listen to each other's point of view as well as challenged each other"

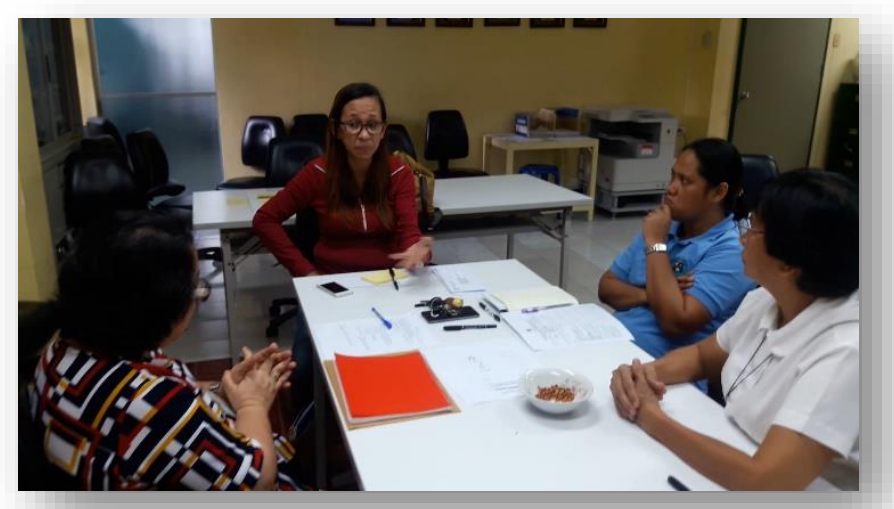

Fg. 14 A Reflection session of Pre-Service Teacher's Supervisors 
Geraldine Villaluz, Mariter Malonjao, Carina Trinidad, Marlon Bojos | ASEAN Journal of Community Engagement | Volume 2, Number 2, 2018

\subsection{Broadened Professional Knowledge}

The fourth result is a confirmation of the theory proposed by social constructivists that knowledge is socially constructed. Supervisors of pre-service teachers have claimed that participation in a professional learning community and applying the processes of a research lesson has broadened one's knowledge in instruction and content. Knowledge received from shared insights and comments in a professional learning community has proven to provide hands on knowledge than costly teacher trainings and or seminar workshops. Supervisors of pre-service teachers gained inspiration and enthusiasm to share the research lesson framework to their respective departments and create professional learning communities as experienced by team members in the following statements:

Teacher 1: "This method has enriched my topic because of the ideas of colleagues"

Teacher 2: "Research Lesson has lessened my feelings of anxiety on being observed knowing that the focus of the observation is on the prepared lesson and student engagement"

Teacher 1: Research Lesson has made me experience multidisciplinary exchange of ideas

Teacher 5: "Documenting our research lesson observations gave me the chance to research on our teaching practices."

During the presentation of the method and results of a professional learning community and research lesson practices of the school of education in a University Research Conference in 2018, Department heads were encouraged to apply the same to their own teaching communities.

\subsection{Contextualized Student Learning Outcome}

One of the unique contributions of a professional Learning Community and Research Lesson process into the teaching profession is the contextualized data that each learning community generates. In this research lesson, the student learning outcome were responses to communities where each of the four classes was involved. Three classes were fielded in local government day cares while one focused in the department outreach activities. Students' involvement in these activities proved to challenge students' interpersonal and intrapersonal social skills, communication leadership and organizing 
Geraldine Villaluz, Mariter Malonjao, Carina Trinidad, Marlon Bojos | ASEAN Journal of Community Engagement | Volume 2, Number 2, 2018

skills among others. Excerpts from students 'reflection in Research Lessons 2 and 3 provided encouraging remarks:

On Communication and Facilitating Skills

Student 1: "It was a good strategy that each class was tasked to be an expert of one topic because it exercised our skills in communication, listening, facilitating and organizing."

Student 2: "I was happy to have learned so much from other peoples' ideas"

Student 3: "I am happy to have learned about concept maps"

-Student reflection of Post Lesson 3

On the Construction of Knowledge

Student 6: "I was happy to hear the thoughts in the synthesis of groups from other classes. Their sharing made me reflect on my own experience."

Student 5: "The learning environment gave us the freedom to share and go around. I did not feel controlled"

Student 3: "I learned from the way our facilitator managed our group sharing. Each of us was given equal time for sharing. I would do the same when it is my turn"

-Student reflection of Post Lesson 2

These excerpts of student reflection show how collaborative lesson planning by a multidisciplinary group respond to diverse student needs. In all lesson planning sessions team members always made it a point to apply group tasks and exchange of groups which noticeably excited many students because of their desire to meet new friends from other classes each session. Collaborative lesson planning enables students to share individual personal skills while learning new lessons from the lessons prepared.

\section{Conclusion}

The study achieved its three main objectives: a) it identified the challenges and opportunities in the teaching of the Social Dimensions of Education course; and b) it illustrated and analyzed the effects of community engagement among faculty members using the application of the research lesson framework to student learning, teaching and learning, reflection practice, and research performance. Therefore, the results of this study can conclude that benefits received from individual teaching-learning preparations 
Geraldine Villaluz, Mariter Malonjao, Carina Trinidad, Marlon Bojos | ASEAN Journal of Community Engagement | Volume 2, Number 2, 2018

can only remain within the teacher's personal experiences. In individual planning, misconception of concepts in the teaching-learning process and the learning performance of students may be corrected only during observations by the chair, coordinator, or dean. On the other hand, community engagement in constant planning, observation, and critical reflection can facilitate positive changes in the teaching profession that allow for the sharing of strategies in teaching and learning, reading of updated literature, transformation of student performance, and more effective sharing of professional knowledge.

However, there are also limitations seen in research lessons; in situations where a limited number of faculty members are assigned to all sections of their specialized field, a research lesson may not be possible. A second observed limitation is the availability of time. This happens when faculty members are overloaded with teaching units, and the time or space for the processes needed in research lessons may not be available.

Therefore, this study recommends that the school or department leadership create a significant role for effective research lesson implementation as they have the authority to assign teacher loads and arrange course schedules. Time for meeting and implementing planned lessons is an important element in research lessons and this can only be achieved when department chairs or heads of schools synchronize the schedule of loads given to a faculty research lesson team. For a rich research lesson result, courses must be assigned to multidisciplinary faculty members. Finally, the members selected to join professional learning communities and compose the research lesson teams must be faculty members who share the same ideals for teaching-learning and whose first concern is their students' learning development.

\section{References}

70-84, C. (2017, December). The Teacher and the Community, School Culture and Organizational Leadership. CMO 70-84 Series of 2017. Quezon City, Philippines.

CHED. (2004). Commission on Higher Education. Retrieved from ched.gov.ph: www.ched.gov.ph

CM030. (2004). Commission on Higher Education. Retrieved from ched.gov.ph: www.ched.gov.ph 
Geraldine Villaluz, Mariter Malonjao, Carina Trinidad, Marlon Bojos | ASEAN Journal of Community Engagement |

Volume 2, Number 2, 2018

Dewey, J. (1909). The Means and End of Mental Training: The Psychological and the Logical. In J. Dewey, How We Think (p. 57). Boston: D.C. Heath \& Co.

Dewey, J. (1980). Democracy \& Education. The Middle Works, 1899-1924, Volume 9:1916. (J. A. Boydston, Ed.) London and Amsterdam: Southern Ilinois University Press. Retrieved May 28, 2018, from www.gutenberg.org

Dewey, J. (2008). Education as Conservative \& Progressive. In J. Dewey, Democracy \& Education. Guttenberg. Retrieved March 12, 2018, from http://www.gutenberg.org/files/852/852-h/852-h.htm\#link2HCH0006

DuFour, R. (2004). What is a "Professional Learning Community?". Educational Leadership, 1-4.

Hord, S. M. (2009). Professional Learning Communities. JSD, 30 No. 1(Winter), 40-43. Retrieved December 12, 2017, from www.NSDC.org

Lewis, C. (2000). Lesson Study: The Core of Japanese Professional Development. American Educational Research Association (pp. 1-47). Los Angeles: ERIC.

Lewis, C. (2011). National Academies.org. Retrieved from https://sites.nationalacademies.org/cs/groups/dbassesite/documents/webpage/ dbasse_084385.pdf

Makinae, N. (2010). Lesson Study Group. Retrieved from EARCOME5: http://www.lessonstudygroup.net/lg/readings

Makinae, N. (2010). The Origin of Lesson Study. EARCOME5 Japan Society of Mathematical Education. Tsukuba, Japan: EARCOME5.

Mattar, J. (2010). The Comprehensive Handbook of Constructivist Teaching. USA: Information Age Publishing.

Piaget, J. (2001). the Place of Intelligence in Mental Organization. In J. Piaget, The Psychology of Intelligence (pp. 4 - 9). London: Routledge.

Schon, D. (1983). The Reflective Practitioner. (B. Michelsen, Trans.) Retrieved February 21, 2018, from https://www.sopper.dk/speciale/arkiv/book49.pdf

UNE, P. a. (2016, August 4-5). Philippine National Research Center for Teacher Quality. Retrieved from https://www.pnu.edu.ph/rctq/ 
264

Geraldine Villaluz, Mariter Malonjao, Carina Trinidad, Marlon Bojos | ASEAN Journal of Community Engagement | Volume 2, Number 2, 2018

Wang Iverson as cited in Soledad Ulep et. al. (2014). In S. U. al., Lesson Study: Learning More Together, Growing in Practice Together. Quezon City: University of the Philippines National Institute of Mathematics Education. 